\title{
Discussion: The reconstructed Lions' Gate suspension bridge
}

\section{P. G. Buckland and D. D. Matson}

\section{J. Evans, Flint and Neil Partnership}

The authors are to be congratulated on the presentation of this excellent and informative paper about a bold and innovative solution to a common problem being experienced worldwide, namely lack of capacity and increasing problems of maintenance of older structures on key routes over major estuarine crossings. It exemplifies the quality of papers sought for the Bridge Engineering journal of the Institution and meets the stated aims, scope and vision of the journal.

The authors have covered almost every facet of the project in such concise detail that there remain few questions to raise with them. One matter not dealt with in the paper (but possibly already dealt with in one of the references) is the condition of the main cables - in the main body of the wrapped lengths, at the cable clamp positions, at the tower and north cable bent saddles and at the terminations in the anchorages. It would be helpful to know what investigations were carried out to ensure that these vital structural elements were in sufficiently sound condition to justify the major reconstruction of the deck. Some comment about the authors' views on why the cables had stretched, and by how much, would also be useful for future reference.

\section{Authors' reply}

The discusser raises an important point: before hanging an entirely new suspended structure from the cables, it was prudent to determine that the cables themselves were in good condition. In 1978 the east cable was unwrapped at the low end of the north side span, just above the cable bent, and just above the splay saddle inside the anchorage, No deterioration was found, except for some very light corrosion on the underside of the cable near the cable bent.

In the 1980s both main cables were unwrapped and inspected at the centre of the main span when the centre cable bands there were replaced. No corrosion or other damage was found.

In 1997, before undertaking the suspended structure replacement, the west cable was unwrapped and inspected at midspan, and the east cable was unwrapped between the south cable rocker and the south anchorage (a long enough distance to allow some prying apart of the cable strands). The cables were once again found to be in excellent condition, and careful examination revealed that what had previously been identified as 'light rust' was in fact not rust but a product from the sap of the cedar fillers that are inside the wrapping wires.

The cable stretch is presumed to be caused by individual wires bedding down into each other, or at least into the galvanising zinc that coats them, where they cross, as a result of changes in temperature and tension, and clamping at bands and saddles. The main cables were not spun in place: they were at the time the longest suspension bridge cables to be constructed of spiralwound strand. Although they had been pre-stretched at the fabricating plant in Montreal, they were then shipped by rail $5000 \mathrm{~km}$ to Vancouver before they were placed on the bridge, and they may have lost some of the benefits of pre-stretching.

The amounts of stretch were, as given in the paper, about $0 \cdot 029 \%$ for the main cables, and $0 \cdot 1 \%$ for the hangers. Much of this occurred in the few months before the bridge was opened to traffic. 